\title{
Análise das legendas de efeitos sonoros do filme Nosso Lar
}

\section{Analysis of the soundtrack subtitling from the movie Astral City}

\author{
Ana Katarinna Pessoa do Nascimento*
}

Resumo: 0 universo sonoro de um filme é composto pela fala, música e ruídos, também chamados de efeitos sonoros. Sem a tradução para legenda, o espectador surdo ou ensurdecido não tem acesso a esses aspectos das produções audiovisuais, por isso, a legenda para surdos e ensurdecidos (LSE) precisa indicar o falante e os efeitos sonoros. Esta pesquisa buscou analisar a tradução dos efeitos sonoros do filme Nosso Lar (2010). Para tanto, os efeitos sonoros foram anotados a partir de etiquetas discursivas. Os dados revelaram que os efeitos sonoros foram traduzidos sem preocupação com a significação fílmica, já que muitas legendas traduziram os efeitos sonoros de forma aleatória sem se atentar para sua importância ou evolução dentro do filme. Para que o surdo faça a ligação entre enredo e a significação do som, é preciso que o legendista leve em conta que os efeitos sonoros acontecem numa sequência.

Palavras-chave: Efeitos Sonoros; Legendagem para Surdos e Ensurdecidos (LSE); Linguística de Corpus; Tradução Audiovisual.

Abstract: A film sound universe is composed by speech, music and noise, also known as soundtrack. Without subtitling, deaf and hard of hearing audiences do not have access to these audiovisual production's features. For this reason, subtitling for the deaf and the hard-of-hearing (SDH) has to indicate the speaker and the sound effects. This research tried to analyze the translation of the sound effects of the

\footnotetext{
* Doutoranda do Programa de Pós-Graduação em Estudos da Tradução da Universidade de São Paulo. E-mail: katarinnapessoa@gmail.com
} 
NASCIMENTO, A. K. P. DO - Análise das legendas de efeitos sonoros do filme Nosso Lar

movie Astral City (2010). For the analysis, the sound effects and music of this film received discursive tags. The data revealed that the sound effects were translated without taking filmic meaning into account, since many subtitles translated the sound effects at random with little regard to their importance or developments within the film. For the deaf to make the connection between what happens on screen and the sound significance, it is necessary for the subtitler to realize that sound effects occur on a sequence.

Keywords: Sound Effects; Subtitling for Deaf and Hard of Hearing (SDH); Corpus Linguistics; Audiovisual Translation.

\section{Introdução}

No Brasil, o Ministério das Comunicações publicou em 2006 a Portaria 310, oficializando a Norma Complementar $n^{\circ} 1 / 2006$ que estabelecia 0 cronograma de implantação e os requisitos técnicos para tornar a programação das TVs abertas acessível para pessoas com deficiência. Para atender a essa norma, os canais de televisão estão utilizando o sistema de legendagem norte-americano chamado de closed caption. 0 closed caption é um sistema de legendagem fechado, no qual as legendas são visíveis quando acionadas por meio do controle remoto de televisores que disponibilizam esse sistema. Outra característica do closed caption dá-se em relação ao processo de tradução, que consiste na transcrição à letra das falas de um filme ou programa de TV. Este fator, muitas vezes, acarreta em falta de sincronismo entre legenda e imagem (ARAúJo 2004). Pesquisas realizadas na Universidade Estadual do Ceará sugerem que, por ser apenas transcrição da fala e não apresentar características próprias da legendagem, as legendas do closed caption são de difícil leitura e compreensão para os surdos (Franco; ARAújo 2003; ARAújo 2004).

Com relação à recepção de surdos aos efeitos sonoros, em 2009, deu-se início ao Projeto MOLES, pesquisa de recepção coordenada pela Profa. Dra. 
NASCImENTO, A. K. P. DO - Análise das legendas de efeitos sonoros do filme Nosso Lar

Vera Lúcia Santiago Araújo, que procura estabelecer os parâmetros da legendagem para surdos e ensurdecidos no Brasil. Essa pesquisa ocorreu em quatro regiões do país e versou sobre diversas questões técnicas a respeito da LSE. Como bolsista de iniciação científica, a presente pesquisadora acompanhou o andamento do projeto e percebeu que muitos sujeitos sentiam rejeição em relação à tradução de efeitos sonoros. A participante FOR1 ${ }^{1}$ afirmou: "Eu vou direto nas legendas. Meu foco é a legenda. Não dá pra eu prestar atenção no som. Eu sou surda! Você precisa orientá-lo, que ele saiba disso. Não dá pra eu prestar atenção no som."

Nesse contexto, é preciso salientar a importância do som dentro de uma produção fílmica. 0 som gera expectativas, guia o espectador através das imagens e molda a recepção de determinada cena (BORDWELL 2008). Segundo Bordwell (2008), o som é a faceta do cinema mais difícil de ser estudada. Explica que na vida cotidiana, os sons ambientes são apenas um apoio ao que chama mais atenção: as imagens. Por isso, tende-se a perceber o som no cinema da mesma forma. No entanto, salienta que o som pode ter grande impacto e ainda assim permanecer despercebido. 0 autor compreende que, para estudar o som, é preciso ouvir o filme, ao invés de uma análise somente das imagens.

A partir da relevância do som dentro dos filmes, a presente pesquisa surgiu com o escopo de analisar como a tradução de efeitos sonoros tem sido realizada, e se esta tradução está em consonância com a significação do filme. Isso é importante, já que o filme é um texto multimodal, no qual o som representa uma parte importante da significação pretendida pelo diretor. Este trabalho procura responder as seguintes perguntas: 1) Como a legendagem do som contribui efetivamente para a significação do filme Nosso Lar?; 2) Como esses efeitos sonoros foram traduzidos nas legendas para surdos e

\footnotetext{
${ }^{1}$ Os participantes do projeto MOLES foram nomeados de acordo com a sigla do aeroporto de sua cidade e numerados de acordo com a ordem em que eram entrevistados. Nesse sentido temos, por exemplo FOR 1, 2, 3, 4 e 5.
} 
NASCIMENTO, A. K. P. DO - Análise das legendas de efeitos sonoros do filme Nosso Lar

ensurdecidos no filme Nosso Lar; 3) Qual é a relação entre a legendagem e a significação diegética do som? Essas perguntas foram abordadas por meio da metodologia baseada em corpus, com o auxílio do programa de análise linguística WordSmith Tools (WST).

\section{O som no Cinema}

Em uma primeira impressão, pode-se pensar que os sons são apenas um acompanhamento da verdadeira base do cinema: as imagens. Isso acontece porque o som pode permanecer despercebido, enquanto atinge efeitos importantes para a compreensão de um filme, muitas vezes alterando e direcionando a maneira como percebemos as imagens (CHION 2008). Para uma produção fílmica original e de qualidade, é preciso fazer com que o público consiga integrar som e imagem como um todo sem diferenciação (HUNTER 2008).

Hunter (2008) entende que todos os sons de um filme são tomados em relação à tela. Sons on screen são aqueles cuja fonte é visível durante a cena e é incorporado nela. 0 papel dos sons on screen dependerá de alguns fatores, tais como de onde vem, o que o origina, e por que aparece naquele momento. No entanto, é possível dizer que o seu papel predominante é reforçar a imagem. Os sons off screen, no entanto, são aqueles cuja fonte claramente não está presente em cena e podem causar uma reação nos personagens que aparecem em cena, mas também podem ser percebidos apenas pela audiência para aumentar a ligação do espectador com a trama.

Sons on screen e off screen diferem de sons diegéticos e não diegéticos. O termo diegese é relativo no cinema e em outros produtos audiovisuais àquilo que ocorre dentro da ação narrativa ficcional do próprio filme. Se um personagem reage a um som off screen, esse som participa da trama e, portanto, é diegético. Nem todos os sons off screen são diegéticos. 
NASCImENTO, A. K. P. DO - Análise das legendas de efeitos sonoros do filme Nosso Lar

Na clássica cena do assassinato no chuveiro em Psicose (Psycho, 1960) de Alfred Hitchcok, cada facada é acompanhada por ruídos que só são percebidos pelos espectadores. Esse exemplo mostra como os designers de som usam os sons de maneira criativa para intensificar a percepção, contribuindo para um maior envolvimento emocional do público. É importante notar que a música de fosso (ou não-diegética), segundo Chion (2008), é aquela que acompanha a imagem a partir de uma posição off, ou seja, está afastada do local, tempo e da ação em cena, enquanto música de tela (ou diegética) é aquela que provém do local da ação, mesmo que provenha do rádio ou televisão, ou não esteja visível em cena por qualquer outro motivo. Esse tipo de música é capaz de ultrapassar as barreiras on e off screen ora como parte da cena, ora como música de fosso.

Quanto à música do cinema, cada trecho de música do filme é chamado de cue. As cues são utilizadas para salientar ocorrências ou interligar cenas, e até mesmo rotular eventos. Bordwell (2008) entende que a escolha e a combinação dos sons podem criar padrões dentro da obra fílmica. Ritmo, melodia e harmonia da música afetam a reação emocional do espectador. Dessa forma, uma melodia ou trecho de música pode ser associado com determinado personagem, situação ou idéia, criando motifs ${ }^{2}$ musicais. 0 uso da música pode ajudar a montar uma história cujo enredo acompanhe inúmeros personagens e localizações, permitindo criar uma unidade ao filme e garantir a fluidez da narrativa. O filme Em algum lugar do passado (Somewhere in time, 1980) utiliza essa técnica. A câmera percorre um ambiente enquanto é possível ouvir uma música de fundo. Ao focalizar o personagem principal, a plateia percebe que a música é proveniente do rádio, quando o personagem o desliga, o espectador continua ouvindo a canção. Esse exemplo é apenas para demonstrar como é tênue essa distinção, uma vez que

\footnotetext{
${ }^{2}$ Uma melodia ou trecho de música podem ser associados com determinado personagem, situação ou idéia, criando motifs musicais, que se repetirão no decorrer do filme.
} 
NASCIMENTO, A. K. P. DO - Análise das legendas de efeitos sonoros do filme Nosso Lar

há outras ambiguidades a serem consideradas, como quando a música de tela é acompanhada pela música de fosso com orquestra (CHION 2008).

\title{
2. Efeitos sonoros e Legendagem para Surdos e Ensurdecidos
}

\begin{abstract}
Os efeitos sonoros na LSE são adicionados para contemplar aspectos importantes provenientes de informações acústicas não-verbais. Neves (2005) aponta que, em alguns casos, isso é feito por meio de uma operação intersemiótica, pois transforma mensagens não verbais em mensagens verbais, ou seja, as mensagens são transmutadas de um sistema para outro diferente. A autora ainda afirma que:
\end{abstract}

Sabendo que o espectador surdo possui pouco (ou nenhum) acesso às mensagens que derivam dos códigos acústicos, o tradutor deverá ser um leitor proficiente de textos intersemióticos, além de reformular tanto os elementos acústicos verbais e não-verbais e encontrar meio de expressá-los através de palavras escritas, mesmo que possam ser de naturezas diferentes3. Quando se legenda para esse público em específico, cabe ao tradutor transformar em códigos visuais tanto os diálogos que são ouvidos quanto os efeitos sonoros que são percebidos de maneira a serem integrados com o filme da forma mais natural possível. (pp. 131)

\footnotetext{
${ }^{3}$ Minha tradução para "In the knowledge that the deaf receiver will have little (or no) access to many of the messages deriving from acoustic codes, the translator, who will need to be a proficient "reader" of intersemiotic text, will re-word both the verbal and non-verbal aural elements and find ways to express them through visual codes, usually written words, although they could also be of a different nature. When subtitling for these specific audiences, it is up to the translator to turn into visual codes both the dialogues that are heard and the sound effects that are only perceived in such a manner that they will be integrated with the whole in as natural manner as possible".
} 
NASCImENTO, A. K. P. DO - Análise das legendas de efeitos sonoros do filme Nosso Lar

Uma atenção à tradução dos efeitos sonoros de uma obra audiovisual faz-se necessária na medida em que os componentes acústicos não verbais colaboram para a construção de sentido, pois sem eles, a construção do texto audiovisual perde um dos seus elementos significadores. Algumas questões técnicas envolvem a tradução de efeitos sonoros. No Brasil, além de ser apresentada entre colchetes, também é comum o uso de colcheias para traduzir música. Cintas e Remael (2007) entendem que quando a letra da música não é relevante para a trama, não há necessidade de ser traduzida, a menos que haja tempo para tal. Porém, se a mensagem da música for importante para a compreensão da obra, a letra deve ser legendada, como geralmente ocorre em musicais. Segundo os participantes do projeto MOLES, os ritmos musicais não precisariam ser descritos, pois os surdos alegaram que não faz diferença para a compreensão deles se o ritmo é bossa nova, rock ou qualquer outro (ARAúso 2008).

Quanto à necessidade de traduzir todos os sons do filme, Donaldson (apud ARAÚJo 2008) entende que se a ação for visível e compreendida através da imagem, não se faz necessária a tradução, pois o duplo input poderia irritar os surdos. Os dados do projeto MOLES corroboram essa ideia, pois, segundo os participantes, apenas aqueles sons importantes para o acompanhamento da trama, ou que influenciam na ambientação da história de forma mais direta, deveriam ser legendados. Como exemplo podemos citar a legenda [Música alegre] percebida pelos participantes da pesquisa como refletindo o estado de espírito da personagem, ao contrário de [Música instrumental], a qual não foi relacionada como música tema da personagem (ARAújo e Nascimento 2011).

Os parâmetros vistos acima foram testados em pesquisas anteriores (Franco e Araújo 2003; Araújo 2004, 2005, e 2008) com surdos cearenses, era preciso então testar esse modelo com sujeitos das cinco regiões do Brasil. 0 projeto MOLES consiste em pesquisa exploratória na qual foram entrevistados 34 participantes: 10 da região Nordeste, 10 da região Sul, 10 da região 
NASCIMENTO, A. K. P. DO - Análise das legendas de efeitos sonoros do filme Nosso Lar

Sudeste e 4 da região Norte. Eles responderam a um questionário, cujo objetivo era traçar o perfil do informante. 0 questionário pré-coleta versava sobre itens tais como idade, escolaridade, grau de surdez, frequência com que assistia a produções audiovisuais providas de LSE e domínio da língua portuguesa. O perfil geral dos participantes da pesquisa foi de surdos de nascença, universitários, 25 anos, sinalizados ${ }^{4}$ a partir dos 10 anos, além do uso da LSE na televisão.

Muitos dados importantes foram obtidos através dos relatos retrospectivos e das respostas às perguntas 11 e 12 do questionário póscoleta, que versavam sobre as legendas de efeitos sonoros. As perguntas eram respectivamente: Você conseguiu compreender os sons representados nas legendas? Você conseguiu fazer relação entre sons, legendas e imagens?

De maneira geral, pode-se dizer que os participantes perceberam a tradução dos sons, mas apenas quando a legenda tinha ligação direta com o enredo do filme ela foi útil para que eles pudessem harmonizá-la com o contexto fílmico e, assim, tirar conclusões a partir da trilha sonora legendada. Aqueles sons que não colaboravam muito para a construção da trama, podendo até mesmo desviar a atenção do espectador surdo de algo mais importante que ocorre na tela, passaram quase que total e completamente despercebidos. Por conta desses resultados, os dados sugeriram que ao se legendar o som de uma música, é necessária uma qualificação que caracterize sua importância dentro do enredo, para que ela forneça informação relevante a ser agregada para o acompanhamento do filme.

\section{Metodologia}

\footnotetext{
${ }^{4}$ Surdos que sabem a Língua Brasileira de Sinais (LIBRAS).
} 
NASCImENTO, A. K. P. DO - Análise das legendas de efeitos sonoros do filme Nosso Lar

Trata-se de uma pesquisa descritiva de natureza quali-quantitativa, pois procura descrever e analisar a tradução de efeitos sonoros em legendas para surdos e ensurdecidos de filmes brasileiros comercializados em DVD. Essa pesquisa insere-se no campo da Tradução Audiovisual e dos Estudos de Tradução baseada em Corpus, pois envolve o estudo de textos autênticos traduzidos em Língua Portuguesa (LSE de 3 filmes brasileiros em DVD), por meio de anotação de corpus e uso do programa para análise linguística WordSmith Tools. A presente pesquisa tem como objetivo fomentar as discussões no âmbito da Tradução Audiovisual e Acessibilidade, que é o foco dos estudos conduzidos dentro do grupo de pesquisa LEAD ${ }^{5}$ (legenda e audiodescrição) e apoio fincaneiro do CNPq. A presente pesquisadora teve apoio financeiro da FUNCAP - Fundação Cearense de Apoio ao Desenvolvimento Científico e Tecnológico.

Realizou-se no contexto do Laboratório de Tradução Audiovisual (LATAV) da UECE, que tem como objetivo fomentar as discussões no âmbito da Tradução Audiovisual e Acessibilidade.

Lançado em 2010, Nosso Lar (NL) figura na lista dos 60 filmes brasileiros de maior público, ocupando a posição 24. É também o filme mais caro da história do Brasil (custou por volta de 20 milhões de reais) e possui temática espírita:

Baseado no best seller de Chico Xavier, o filme conta a história de André Luiz, um médico bem sucedido que, após sua morte, acorda no mundo espiritual. Lá começa sua nova jornada, de autoconhecimento e transformação, desde os primeiros dias numa dimensão de dor e sofrimento, até ser resgatado e levado para a cidade espiritual Nosso Lar, cidade que dá nome ao filme e que paira nas camadas mais altas da atmosfera terrestre. (ENCARTE DO DVD, 2010)

\footnotetext{
${ }^{5}$ Coordenado pela Profa. Dra. Vera Lúcia Santiago Araújo.
} 
NASCIMENTO, A. K. P. DO - Análise das legendas de efeitos sonoros do filme Nosso Lar

Neste filme, roteiro e direção são assinados por Wagner de Assis. Sucesso de bilheteria e público, NL não foi tão bem recebido pela crítica. 0 site Omelete $^{6}$ acredita que o filme tem empenho técnico, mas retrocesso narrativo, já que o caráter didático do livro não é esquecido em sua versão cinematográfica. Na Folha Ilustrada ${ }^{7}$, o filme foi citado como clichê, pobre e sem graça.

As legendas do filme analisadas foram retiradas do DVD com auxílio do programa SubRip 1.50. Este software reconhece apenas arquivos em extensão VOB, ou seja, no formato de DVD. Após escolhido o arquivo, o programa dá início à extração das legendas. O SubRip funciona por meio de reconhecimento de caracteres e, algumas vezes, alguns caracteres não são identificados pelo programa e devem ser inseridos manualmente, daí em diante o programa passa sempre a reconhecer determinado caractere pelo que foi inserido manualmente. 0 processo todo de extração de legendas dura apenas alguns minutos.

Em seguida, deu-se o processo de anotação do corpus (etiquetagem). Este pressupõe sempre uma análise do corpus cru (O’DonNeLL 1999), ou seja, para que se anote o corpus corretamente, é preciso analisá-lo. 0 tipo de etiqueta utilizada neste trabalho é a etiqueta discursiva, que, segundo Tagnin (2010) consiste em etiquetas que demarcam as partes de um texto, no caso desse trabalho, a tradução de efeitos sonoros. Em primeiro lugar, identificaram-se as legendas de efeitos sonoros, para se ter um controle de quantas e quais etiquetas seriam necessárias. Para tanto, foi inserida a etiqueta $\langle\text { es }\rangle^{8}$ ao início de cada efeito sonoro, e $</$ es $>$ ao final deles.

Uma vez que todos os efeitos sonoros foram identificados, seguiu-se 0 processo de anotação manual das etiquetas presentes no Quadro 1 (esta

\footnotetext{
${ }^{6}$ http://omelete.uol.com.br/cinema/critica-nosso-lar/. Acesso em: nov. 2012.

${ }^{7}$ http://www.folha.uol.com.br/multimidia/podcasts/792832-cheio-de-cliches-filme-espiritanosso-lar-e-pobre-e-sem-graca-ouca-critica.shtml. Acesso em: nov. 2012.

${ }^{8}$ Os parênteses angulares são utilizados nas etiquetas por serem linguagem HTML, que é decodificada pelo programa WST.
} 
NAsCimento, A. K. P. DO - Análise das legendas de efeitos sonoros do filme Nosso Lar

anotação ocorreu sem o auxílio de programas especializados, sendo que a própria pesquisadora inseria as etiquetas nos arquivos de texto das legendas). Para melhor identificar qual etiqueta cada legenda iria receber, os filmes foram assistidos no computador. A cada legenda de efeito sonoro, o filme era parado e então, no arquivo de texto das legendas, era inserida a etiqueta adequada.

No quadro 1 a seguir, a primeira coluna indica os tipos de som, ou seja, as categorias nas quais eles foram classificados, a coluna do meio mostra as etiquetas inseridas nos textos do corpus e a última coluna apresenta um exemplo de legenda para cada etiqueta.

\begin{tabular}{|cll|}
\hline TIPO DE SOM & ETIQUETA & EXEMPLO \\
\hline Som da natureza & $<$ som_nat $>$ & [som de trovão] \\
\hline $\begin{array}{c}\text { Som causado por } \\
\text { animais }\end{array}$ & $<$ som_anim $>$ & $\begin{array}{c}\text { [Trovões e sons de } \\
\text { aves de rapina] }\end{array}$ \\
\hline Som causado pelo & & [Som de gritos \\
homem & & desesperados] \\
\hline Som ficcional & $<$ som_ficc & [Almas zunindo] \\
\hline Som causado por & $<$ obj> & [batidas na porta] \\
\hline Silêncio & $<$ sils & [silêncio] \\
\hline Instrumento Musical & $<$ inst_mus $>$ & [Violinos animados] \\
\hline Música de fosso & $<$ mus_fosso & [Música dramática] \\
\hline Música em tela & $<$ mus_tela $>$ & [Música clássica] \\
\hline Música qualificada & $<$ mus_qualif $>$ & [Música dramática] \\
\hline Música não & $<$ mus_nqualif $>$ & [Piano] \\
\hline qualificada & & \\
\hline
\end{tabular}

Quadro 1: Etiquetas

Os dados foram analisados por meio do software WordSmith Tools versão 5.0. Das três ferramentas disponibilizadas pelo programa, foi utilizada apenas a concord, que consiste em uma ferramenta que extrai as ocorrências 
NASCIMENTO, A. K. P. DO - Análise das legendas de efeitos sonoros do filme Nosso Lar

de uma palavra de busca e mostra essas ocorrências juntamente com seu contexto (TAGNIN 2010). No programa WST, a palavra é dada centralizada, assim sua análise e identificação são facilitadas para o pesquisador. Esse layout é denominado $\mathrm{KWIC}^{9}$, do Inglês Key Word in Context, ou seja, palavrachave em seu contexto (TAGNIN 2010). A análise é facilitada quando se organiza a busca pela ordem alfabética das palavras à esquerda ou à direita. Dessa forma, os padrões se tornam mais visíveis, já que cotextos iguais são agrupados.

As palavras de busca desta pesquisa foram as etiquetas criadas (Segundo Tagnin (2010), palavras de busca são aquelas a partir das quais são geradas as concordâncias). 0 objetivo era listar cada uma das traduções de uma mesma etiqueta para procurar padrões de comportamento no que diz respeito à tradução, além de conexões entre as escolhas do tradutor e o significado do som no filme.

Para facilitar a busca, a pesquisa foi reorganizada por odem alfabética da primeira palavra à direita do nódulo de busca; dessa forma, as legendas iguais apareceram em sequência (Figura 1). Assim, a pesquisadora pôde observar o contexto em que elas apareceram de forma mais prática. Isto posto, foi possível buscar no corpus se diferentes legendas são usadas em situações semelhantes e se legendas iguais são usadas em situações diferentes. A concord facilitou essa análise, pois permitiu que as legendas fossem colocadas em sequência, o que permite a observação de legendas iguais e facilita a busca destas dentro do filme. A partir daí, usando o conhecimento sobre o som no cinema, procurou-se entender as soluções do tradutor e se elas foram bem sucedidas dentro do conhecimento fílmico ou não.

\footnotetext{
${ }^{9}$ Viana (2010) alerta que esse é o único caso em que se emprega o termo palavra-chave para o objetivo de geração de linhas de concordância. 0 termo mais empregado neste sentido é palavra de busca (search word).
} 
NASCIMENTO, A. K. P. DO - Análise das legendas de efeitos sonoros do filme Nosso Lar

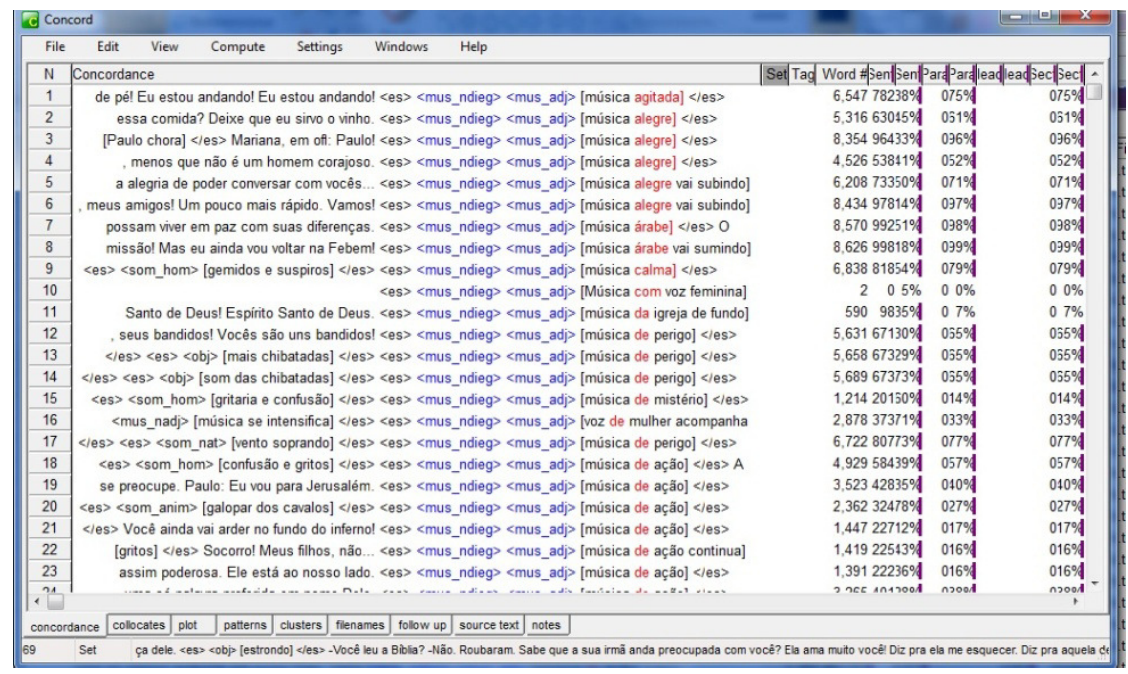

Figura 1: Tela de concordância da ferramenta Concord

Além dos dados linguísticos extraídos pelo WST, o trabalho também recorreu ao filme para analisar as traduções dos efeitos sonoros. As legendas de efeitos sonoros são traduções dos sons do filme e, por isso, se fez necessário o uso do filme para comparar a tradução dos efeitos sonoros com o que estava sendo passado em tela.

Após os procedimentos acima descritos, o corpus estava pronto para análise e interpretação dos dados gerados pelo software e pelo estudo da função do som no filme em questão.

\section{Efeitos sonoros no filme Nosso Lar}

André Luiz é o personagem central de Nosso Lar. Sempre que aparece em tela seus feitos são acompanhados de uma mesma música, caracterizando motif do personagem. Na legendagem, quase todas as aparições de André Luiz foram acompanhadas da inserção [Música Suave] (legenda 15 e 108, quadro 2), apesar de algumas legendas terem escapado deste motif. O ideal seria manter 
Nascimento, A. K. P. Do - Análise das legendas de efeitos sonoros do filme Nosso Lar

legendas iguais em todas as cenas que remetem a cada motif, ou seja, manter [Música Suave] em todas as legendas para os feitos de André Luiz.

\begin{tabular}{|l|c|l|}
\hline$N^{\circ}$ Legenda & Imagem & Legenda \\
\hline 15 & [Música suave] & \\
\hline 108 & [Música suave] & \\
\hline
\end{tabular}

Quadro 2: Música tema de André.

A ausência de ligação entre legenda e contexto fílmico ocorreu com a tradução da Sonata ao Luar de Beethoven. Essa mesma cue foi traduzida inicialmente por [Música clássica] (legenda 576, quadro 3) e posteriormente por [Moonlight Sonata] (legenda 1036, quadro 3). A sonata foi ouvida por André em Nosso Lar e, mais tarde, ao visitar sua casa na Terra, sua presença fez a sua filha tocá-la no piano. Para o espectador surdo, possivelmente não será possível fazer a inferência entre as duas cenas, pois a informação não foi repassada através da legenda. Novamente, o ideal seria repetir uma mesma legenda para um mesmo som.

\begin{tabular}{|l|c|l|}
\hline $\mathrm{N}^{\circ}$ Legenda & Imagem & Legenda \\
\hline 576 & [Música clássica] \\
& & \\
\hline
\end{tabular}


NASCIMENTO, A. K. P. DO - Análise das legendas de efeitos sonoros do filme Nosso Lar

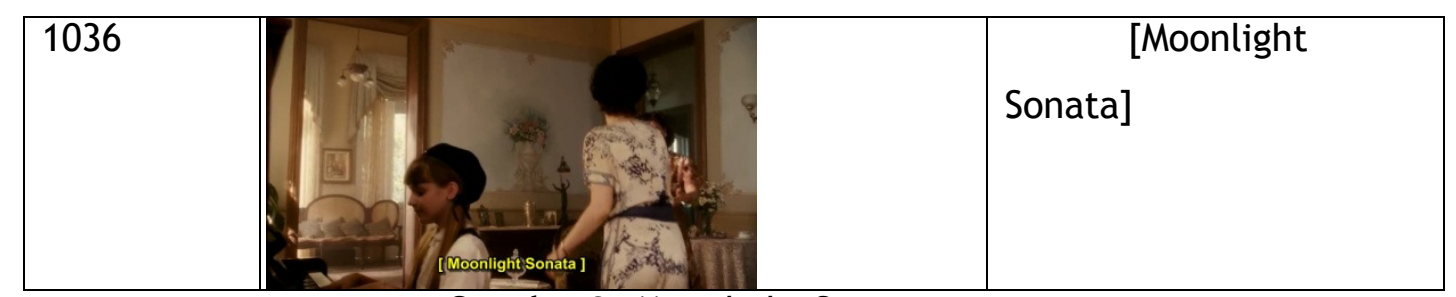

Quadro 3: Moonlight Sonata

Um exemplo de boa tradução de som em NL foi [porta batendo] (quadro 4, legenda $n^{\circ}$ 999). Essa passagem corresponde ao momento em que André Luiz visita sua família e encontra sua esposa casada com um homem doente. André se enfurece e parte da casa com bastante ciúmes, batendo a porta. 0 efeito de sua saída é sentido até mesmo pelas pessoas vivas. A tradução foi necessária, pois sem ela o espectador surdo não poderia saber o que chama atenção dos personagens que se voltam de maneira abrupta. 0 uso do verbo "bater" indicou intensidade na ação de fechar a porta, o que foi o caso com André.

0 mesmo aconteceu com a legenda [coisas batendo] (legenda 802, quadro 4) que de início causou estranheza por sua indefinição, já que o termo “coisas” não corresponde objetivamente a algo em cena. Todavia, nessa cena em particular, não é relevante ao espectador saber o ruído causador do barulho, mas apenas saber que algo chamou a atenção do personagem que se voltou abruptamente. Nos dois casos, houve o fenômeno da acusmatização (CHION 2008).

\begin{tabular}{|l|c|c|}
\hline$N^{\circ}$ Legenda & Imagem & Legenda \\
\hline 802 & [coisas batendo] & \\
\hline 999 & & \\
\hline & & \\
\hline
\end{tabular}

Quadro 4: objetos acusmatizados em NL 
NASCIMENTO, A. K. P. DO - Análise das legendas de efeitos sonoros do filme Nosso Lar

Uma legenda bastante problemática foi [Vento] (legenda 90, quadro 5). Essa legenda aparece quando André é declarado como morto. Neste momento, a tela começa a escurecer e ouvem-se sons que remetem ao Umbral (de acordo com o filme, Umbral é o local onde as almas vão para purgar suas imperfeições), como se este o chamasse. Essa mesma situação foi traduzida em outra cena por [Som do Umbral] (legenda 1000, quadro 5). Com a legenda [Vento] a referência ao Umbral fica descaracterizada, sendo mais difícil ao espectador surdo fazer a inferência da função pretendida para aquele som. Importante notar que o mesmo som ocorre outras vezes na transição de imagens da Terra para o Umbral, porém o legendista optou em traduzir este som apenas nas cenas das legendas 90 e 1000. Novamente, o ideal seria utilizar a legenda [Som do Umbral] em todas as cenas com este tipo de som, pois ela remete diretamente ao que acontece em tela.

\begin{tabular}{|l|l|l|}
\hline$N^{\circ}$ Legenda & Imagem & Legenda \\
\hline 90 & [Vento] \\
\hline 1000 & [Som do Umbral] & \\
\hline & & \\
\hline
\end{tabular}

Quadro 5: som ficcional do Umbral

Diante do que foi exposto acima, pode-se concluir que a legendagem do filme Nosso Lar muitas vezes apresenta traduções iguais para diferentes sons e traduções diferentes para os mesmos sons, ou seja, não há um padrão nas traduções. Isso é ocasionado por não haver preocupação com a significação dos efeitos sonoros do filme. 
NASCImENTO, A. K. P. DO - Análise das legendas de efeitos sonoros do filme Nosso Lar

\section{Discussão de resultados}

Os resultados obtidos sugerem que a legendagem do filme Nosso Lar não se preocupa com a tradução de efeitos sonoros, pois os dados sugerem que estes não foram legendados a partir da função de cada som dentro do enredo fílmico.

A metodologia baseada em corpus foi bastante eficaz para este estudo, porque permitiu a categorização dos tipos de sons traduzidos. A partir da possibilidade de estudar cada categoria em separado, o estudo se tornou mais dinâmico, sendo possível a observação de cada legenda em contexto. No entanto, além da observação do arquivo de texto da legenda, foi necessário sempre recorrer ao filme, enquanto texto multimodal. Dessa forma, cada legenda foi comparada não só às outras legendas da mesma categoria, mas ao seu respectivo som no filme. Assim, foi possível perceber se cada legenda repetida era usada no mesmo contexto ou não, e se corroborava com a significação do filme.

Foi possivel concluir que a legendagem da trilha sonora pode contribuir efetivamente para a significação do filme Nosso Lar. Para tanto, é preciso que o legendista leve em consideração a função de cada som legendado. Dessa forma, as categorias (etiquetas) em que foram divididos os tipos de som nesta pesquisa, ajudam o legendista a antever o papel de cada som, e assim, atribuir às legendas igual importância que estes possuem dentro do filme. A legenda não deve chamar mais a atenção do espectador surdo do que o som o faria com o espectador ouvinte. 0 contrário também não pode acontecer. Se estes dois fatores estiverem em consonância, entende-se que a legenda de efeitos sonoros contribui para a significação dos filmes com LSE da mesma forma que o som contribui para a significação dos filmes para os ouvintes.

Resumindo, ligações entre cenas e acontecimentos (como por exemplo os sons provenientes do Umbral e os acontecimentos marcantes da vida de André Luiz) que têm implicações importantes para o filme, poderiam passar 
NASCIMENTO, A. K. P. DO - Análise das legendas de efeitos sonoros do filme Nosso Lar

despercebidas pelo espectador surdo, o que pode acarretar em perda de conteúdo fílmico gerador de sentido.

O tema deve ser alvo de mais estudos por parte de profissionais e acadêmicos, pois, como já dito, a trilha sonora de um filme também gera significados. O não acesso a esta pode dificultar a compreensão de espectadores surdos ou ensurdecidos.

Este trabalho mostrou a necessidade de se recorrer ao contexto fílmico para embasar a transformação de um som em palavras. Não se fala aqui em expertise em cinema, mas em conhecimentos cinematográficos que permitam traduções coerentes com o enredo. A LSE não é apenas a reprodução escrita da fala, mas há que se observar todos os parâmetros técnicos próprios à legendagem interlingual, caracterizando-se também como atividade intelectual, que deve ser estudada e valorizada.

É importante ressaltar que a presente pesquisa não desconsidera o esforço dos produtores do filme Nosso Lar em proporcionar acessibilidade. 0 que se pretende é fomentar a preocupação em produzir LSEs de qualidade, que permitam não apenas o acesso a filmes, mas também facilitem o entretenimento proporcionado pela possibilidade de apreensão de todos os aspectos relacionados às obras audiovisuais, promovendo o desenvolvimento de uma cultura fílmica por parte de surdos e ensurdecidos.

\section{Referências}

Araújo, V. L. S.; Nascimento, A. K. P. Investigando parâmetros de legendas para surdos e Ensurdecidos no Brasil. In: Frota, M. P.; Martins, M. A. P. (Orgs.). Tradução em Revista, v. 2, pp. 1-18, 2011.

Araúso, V. L. S. Por um modelo de legendagem para Surdos no Brasil. In: VERAS, V. (Org.). Tradução e Comunicação, Revista Brasileira de Tradutores, São Paulo: UNIBERO, n. 17, pp. 59-76, 2008. 
NASCImENTO, A. K. P. DO - Análise das legendas de efeitos sonoros do filme Nosso Lar

ARaúso, V. L. S. Subtitling for the deaf and hard-of-hearing in Brazil. In: Orero, P.; Remael, A. (Orgs.). Media for All: Subtitling for the Deaf, Audio Description and Sign Language. Kenilworth: Nova Jersey, EUA: Rodopi, v. 30, pp. 99-107, 2007.

Araúuso, V. L. S. A legendagem para surdos no Brasil. In: LIMA, P. L.C.; Araújo, A. D. (Orgs.). Questões de Linguística Aplicada: Miscelânea. Fortaleza: EdUECE, pp. 163-188, 2005.

Araújo, V. L. S. Closed subtitling in Brazil. In: Orero, P. (Org.). Topics in Audiovisual translation. Amsterdã: John Benjamins Publishing Company, v. 1, pp. 199-212, 2004.

BORDWELL, D; THOMPSON, K. Film art: an introduction. New York: McGraw Hills, 2008.

CHION, M. A audiovisão: som e imagem no cinema. Lisboa: Edições texto \& grafia, 2008.

Díaz Cintas, J; Remael, A. Audiovisual Translation: Subtitling. Manchester: St. Jerome Publishing, 2007.

Em algum lugar do passado. Direção: Jeannot Szwarc. Universal Pictures, 1980. 1 DVD (103 min), região 4, color., legendado (em português).

Franco, E; Araúso, V. L. S Reading Television: Checking Deaf People's Reactions to Closed Subtitling in Fortaleza, Brazil. In: GAMBIER, Y. (Org.). The Translator, v. 09, n. 2, pp. 249-267, 2003.

HUNTER, C. The use of sound effects and stylised ambiences in filmmaking, 2008. Disponível em: www. freedownload.is/pdf/cinema-sound-effects. Acesso em: 15 mar. 2012.

NEVES, J. Audiovisual translation: subtitling for the deaf and hard of hearing. Tese (Doutorado). Universidade de Surrey Roehampton, Inglaterra, 2005. Disponível em: www.rrp.roehampton.ac.uk/artstheses/1. Acesso em: 15 jan. 2012.

Nosso Lar. Direção: Wagner de Assis. Brasil: Fox do Brasil, 2010. 1 DVD (102 min), região 4, color., legendas (para surdos em português) e audiodescrição.

O'DonnelL, M. B. The Use of Annotated Corpora for New Testament Discourse Analysis: A Survey of Current Practice and Future Prospects. In: PORTER, S. E.; ReED, J. T. (eds.). Discourse Analysis and the New Testament: Results and Applications. Sheffield: Sheffield Academic Press, pp. 71-117, 1999. 
NAscimento, A. K. P. DO - Análise das legendas de efeitos sonoros do filme Nosso Lar

Psicose. Direção: Alfred Hitchcock. Estados Unidos: Universal Pictures, 1960. 1 DVD (109 min), região 4, color., legendas (chinês, coreano, espanhol, inglês, português, tailandês).

TAGNIN, S. E. O. Glossário de Linguística de Corpus. In: VIANA, V.; TAGNIN, S. E. O. (Orgs.). Corpora no ensino de línguas estrangeiras. São Paulo: Hub Editorial, pp. 357-361, 2010. ISBN: 978-85-63623-66-9.

Recebido em: 28 ago. 2015 Aprovado em: 30 out. 2015 